\title{
Tripodal Osmium Polypyridyl Complexes for Self-Assembly on Platinum Nanoparticles
}

\author{
Pablo Contreras-Carballada, ${ }^{\dagger}$ Fabio Edafe, ${ }^{\ddagger}$ Frans D. Tichelaar, ${ }^{\S}$ Peter Belser, ${ }^{*, \neq}$ Luisa De Cola, ${ }^{*, l}$ \\ and René M. Williams ${ }^{*,+}$ \\ †Molecular Photonics Group, Van’t Hoff Institute for Molecular Sciences, Universiteit van Amsterdam, Science Park
904, P.O. Box 94157, 1090 GD Amsterdam, The Netherlands
${ }^{\ddagger}$ Department of Chemistry, University of Fribourg, Chemin du Musée 9, 1700 Fribourg, Switzerland
§ Kavli Institute of Nanoscience, National Centre HREM, Lorentzweg 1, 2628 CJ Delft, The Netherlands
"Physikalisches Institut, Westfälische Wilhelms-Universität Münster, Mendelstrasse 10, D-48149 Münster, Germany
}

\begin{abstract}
The combination of platinum nanoparticles with a tripodal osmium complex that anchors to the metal surface leads, under visible light irradiation, to the formation of solvated electrons. The formation kinetics is limited by the detachment of the electron from the platinum surface into the solution, the particle showing a type of capacitor behavior.
\end{abstract}

SECTION: Electron Transport, Optical and Electronic Devices, Hard Matter

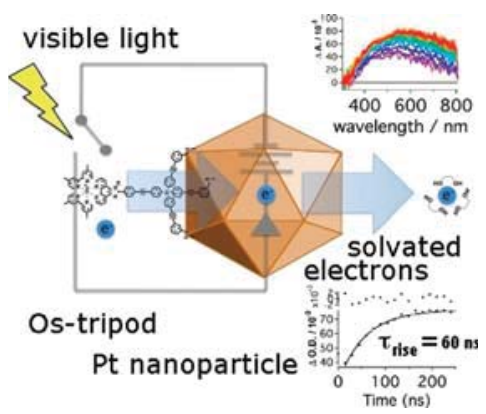

$\mathrm{O}$ rganometallic complexes self-assembled on metal nanoparticles (MNPs) have received increased attention, especially with respect to their photocatalytic and photoluminescent properties. ${ }^{1-4}$ Functionalized tripodal molecules, also named molecular caltrops, are ideal candidates for these systems because their design implies a very well-defined surface attached structure. The tripodal geometry was conceived by Gossauer and coworkers $^{5-7}$ and was further developed by, for example, Tour ${ }^{8}$ and Gallopini. ${ }^{9-11}$ A silicon-based tripod center with three thioacetate groups, ${ }^{12}$ the fourth prong bearing the photo- and electroactive osmium center with two 4,4'-dimethyl-2,2' -bipyridyl (dmbpy) and one imidazo-phenanthroline ligand, was used here $^{13-18}$ (Os-trip, see Chart 1) as well as two reference compounds (e.g., $\left[\mathrm{Os}(\mathrm{bpy})_{3}\right]^{2+}$ see Supporting Information $\left.[\mathrm{SI}]\right){ }^{19}$

The formation of solvated electrons is a remarkable process in which electrons are trapped within a solvent cage. The generation of such trapped charges requires rather drastic chemical conditions or strongly ionizing (UV) radiation (e.g., pulse radiolysis). ${ }^{20}$ Here we describe, for the first time to our knowledge, the use of green visible light to generate solvated electrons.

We show that excitation of the Os-trip that is attached to Pt MNPs results in total emission quenching, attributed to electron transfer to the particle. This process is followed by slow electron detachment from the particle, the solvent playing a crucial role in accommodating the electron in solution in the form of a solvated electron.
The Os-trip complex in acetonitrile was surface anchored by mixing with a citrate-stabilized Pt-MNP solution and the formed nanocomposite was isolated. ${ }^{21,22}$ The attachment was monitored with IR, UV-vis, and emission. (See the SI.) Sulfur-containing groups typically displace the citrate on the platinum surface due to the higher affinity of these groups to the noble metal. The carbonyl bond of the thioacetate group of Os-trip, present at $1690 \mathrm{~cm}^{-1}$ with medium intensity in the IR, is not visible in the assembled nanocomposite because the structure of the vibrational band shifts and changes to one broad band, indicating that during the approach and attachment of the tripod to the metal surface, the thioacetate hydrolyses result in a platinum-sulfur bond, displacing the citrate. ${ }^{8}$ The UV-vis spectra of the particletripod nanocomposite, and its components, are shown in Figure 1A. The observed superposition of the individual components of the spectra is comparable to other examples. ${ }^{23}$ The HRTEM (Figure 1B) shows a good size distribution $(2 \pm 0.4 \mathrm{~nm})$. The photophysical properties of Os-trip are similar to those of the reference complexes (e.g., $\left[\mathrm{Os}(\mathrm{bpy})_{3}\right]^{2+}$ ), although slightly modified by the Si-atom. The attachment of Os-trip to the particle, however, quenches the emission of the chromophore. (See the SI.) 
Chart 1. Molecular Structure of Os-trip

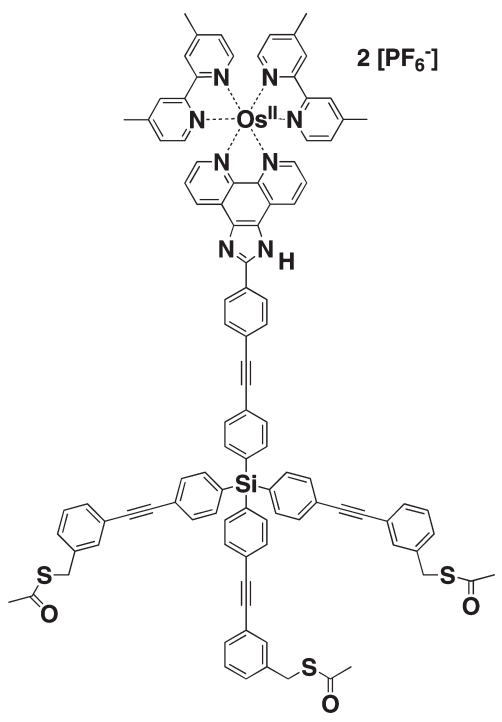

(A)

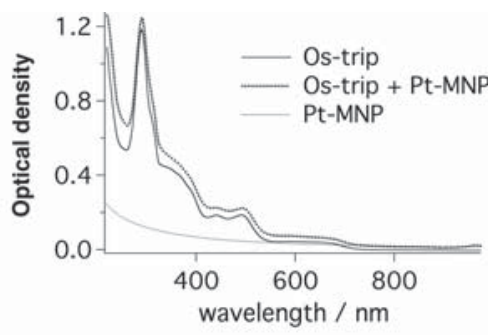

(B)

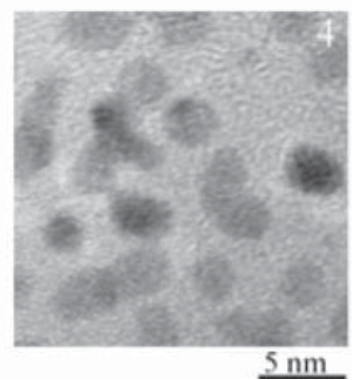

Figure 1. (A) UV-vis of components and composite. (B) HR-TEM of the nanoparticles.

Transient absorption spectroscopy on the nanosecond time scale shows clear differences in the excited state processes of the individual components and the nanocomposite (Figure 2). Whereas the particles show no feature in their transient spectrum, the osmium complex itself exhibits a typical spectrum for polypyridine complexes with the strong ${ }^{1}$ MLCT bleaching between 400 and $550 \mathrm{~nm}$ as well as the ${ }^{3}$ MLCT bleach seen at $630 \mathrm{~nm}$. The bipyridine radical anion of the Os-bpy complex has positive absorption bands that appear below $400 \mathrm{~nm}$ (the emission lifetime of Os-trip is $\sim 45 \mathrm{~ns}$ ). ${ }^{24}$ The assembly of Os-trip on the platinum shows a very different behavior. The features of the osmium complex are masked, and a broad band over the whole spectral region grows within 40-60 ns depending on the solvent used (Figures 2D and 3). In dioxane, this band then decays in 50 $\mathrm{ns}$, having, however, also a longer component $\left(\tau_{\text {decay }} \approx 15 \mu \mathrm{s}\right)$. These lifetimes are in good agreement with kinetic studies on
A)

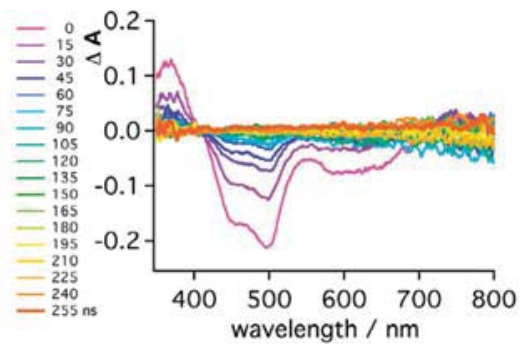

B)

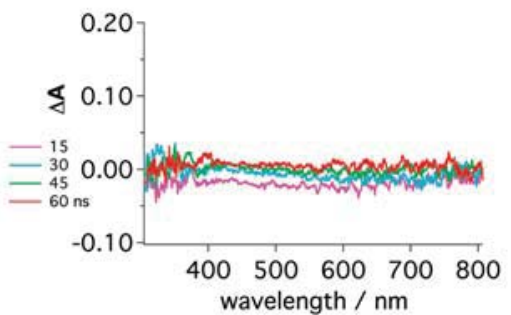

C)

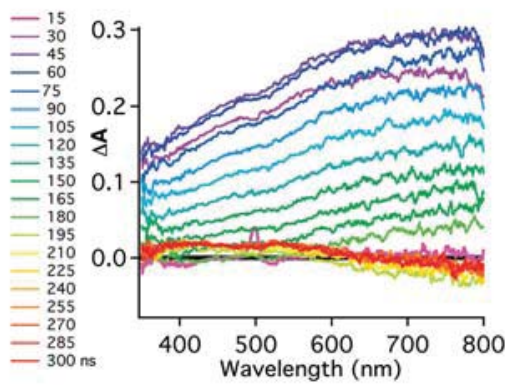

D)

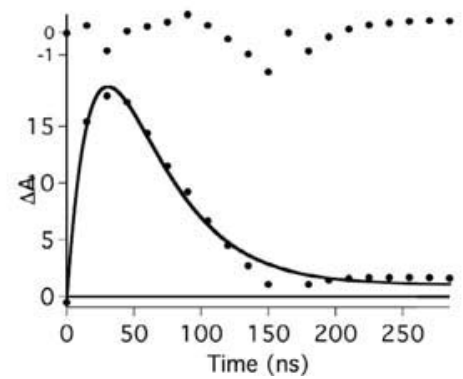

Figure 2. Transient absorption spectra (with zero line) of Os-trip and Pt-MNP $(A, B)$ and the nanocomposite $(\mathrm{C})$ in deaerated dioxane with the formation and decay kinetics (at $400-500 \mathrm{~nm}$ ) of the solvated electron (D); the excitation was at $500 \mathrm{~nm}, 20$ frames recorded with 150 accumulations per frame. Incremental time delay is $15 \mathrm{~ns}$ for all. (The legends show the times of the traces with rainbow color scheme, from violet to red.)

solvated electrons in water and ammonia. ${ }^{25} \mathrm{We}$ attribute the quenching process to a photoinduced electron transfer from the osmium(II) to the platinum nanoparticle. The transferred electron is then trapped on the metal surface and solvated. ${ }^{26-28}$ Hydrated electrons present very broad absorption features in the visible part of the spectrum with a maximum in the near-infrared region of the spectrum. ${ }^{29}$ If the solvent is other than water (or a protic solvent), then the maximum of this very broad band is shifted further to lower energies. ${ }^{30-33}$ We were able to see convincing features of the solvated electron in ethylene glycol, with a maximum for the absorption band at $600 \mathrm{~nm}^{34-36}$ (Figure 3).

In ethylene glycol, the formation of the band corresponding to the solvated electron is relatively slow $\left(\tau_{\text {rise }}=60 \mathrm{~ns}\right)$. For Os-trip itself, we have determined that $\tau_{\text {decay }}=45 \mathrm{~ns}$. If we take into account this lifetime, the limiting step for the formation of the 
A)

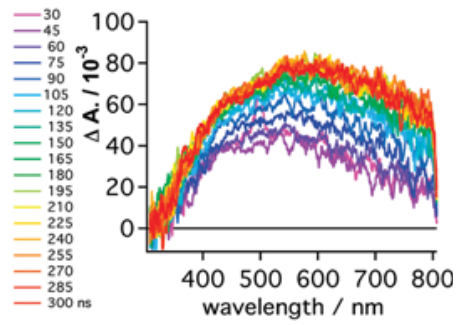

B)

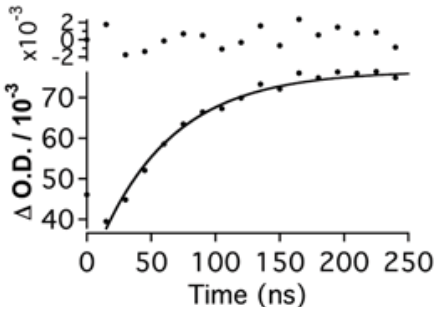

Figure 3. (A) Transient absorption spectrum of the Os-trip-Pt-MNP assembly after excitation at $500 \mathrm{~nm}$ in ethylene-glycol. The broad band is centered at $600 \mathrm{~nm}$ and has a rise time of $60 \mathrm{~ns}$ (B, at $600 \mathrm{~nm}$ ). $15 \mathrm{~ns}$ increment per frame with 500 accumulations per frame. (The legends show the times of the traces with rainbow color scheme, from violet to red.)

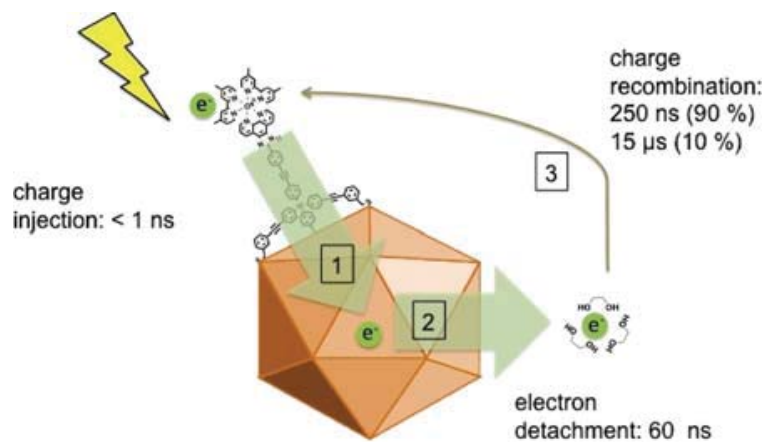

Figure 4. Schematic representation of the chemical steps and kinetics occurring in the nanocomposite in ethylene glycol.

solvated electron has to be the release of the electron from the platinum surface into the solution. The quantum yield (number of electrons produced/number of photons absorbed) was estimated to be $\sim 4 \%$ in ethylene glycol. (See the Supporting Information.) Kinetic observations and correlated chemical steps are combined in Figure 4. Attempts to trap the solvated electron from the solution with a viologen were made. (See the Supporting Information.) Further experiments are currently in progress and will be published separately.

Self-assembly of thioacetate-functionalized tripodal molecules containing an osmium polypyridyl complex onto platinum nanoparticles has been accomplished. Photoinduced interactions between the two components indicate charge transfer from the osmium complex to the particle, followed by surface detachment of the electron. A long-lived solvated electron is formed. The signal corresponding to this solvated electron has a rise time of 40 to $60 \mathrm{~ns}$ and a lifetime that lies in the $50 \mathrm{~ns}$ range with a long component of $15 \mu \mathrm{s}$, indicating a faster disappearance of most of the solvated electrons from the solution and a residual concentration that remains solvated on the longer time scale. Prospective new photocatalytic systems using these concepts are envisioned.

\section{ASSOCIATED CONTENT}

Supporting Information. Compounds used and their photophysical properties, synthesis of Pt-MNP and the nanocomposite, IR and emission of attachment, nanosecond and femtosecond transients of reference compounds, and setups used.

\section{AUTHOR INFORMATION}

\section{Corresponding Author}

*E-mail: decola@uni-muenster.de (L.D.); Peter.Belser@unifr.ch (P.B.); R.M.Williams@uva.nl (R.M.W.).

\section{ACKNOWLEDGMENT}

We thank EU-MRTN-CT-2003-504233 for funding. This research was supported by The Netherlands Research School Combination Catalysis (NRSCC).

\section{REFERENCES}

(1) Hranisavljevic, J.; Dimitrijevic, N. M.; Wurtz, G. A.; Wiederrecht, G. P. Photoinduced Charge Separation Reactions of J-Aggregates Coated on Silver Nanoparticles. J. Am. Chem. Soc. 2002, 124, 4536-4537.

(2) Ray, K.; Badugu, R.; Lakowicz, J. R. Distance-Dependent MetalEnhanced Fluorescence from Langmuir-Blodgett Monolayers of AlkylNBD Derivatives on Silver Island Films. Langmuir 2006, 22, 8374-8378.

(3) Pompa, P. P.; Martiradonna, L.; Della Torre, A.; Della Sala, F.; Manna, L.; De Vittorio, M.; Calabi, F.; Cingolani, R.; Rinaldi, R. MetalEnhanced Fluorescence of Colloidal Nanocrystals with Nanoscale Control. Nature Nanotechnol. 2006, 1, 126-130.

(4) Tanaka, H.; Mitsuishi, M.; Miyashita, T. Luminescence Enhancement of Ruthenium Complexes in Polymer Nanosheet by Surface Plasmon Resonance of Metal Nanoparticle. Chem. Lett. 2005, 34, 1246-1247.

(5) Papamicael, C. A.; Mongin, O.; Gossauer, A. Synthesis of C-1and C-3 Nu-Symmetric Porphyrin Trimers Based on Triphenylmethane Cores. Monatsh. Chem. 2007, 138, 791-796.

(6) Monguin, O.; Gossauer, A. Synthesis of Nanometer-Sized Homo- and Heteroorganometallic Tripodaphyrins. Tetrahedron 1997, $53,6835-6346$

(7) Monguin, O.; Gossauer, A. Tripodaphyrins, a New Class of Porphine Derivatives Designed for Nanofabrication. Tetrahedron Lett. 1996, 37, 3825-3828.

(8) Yao, Y.; Tour, J. M. Facile Convergent Route to Molecular Caltrops. J. Org. Chem. 1999, 64, 1968-1971.

(9) Thyagarajan, S.; Liu, A.; Famoyin, O. A.; Lamberto, M.; Galoppini, E. Tripodal Pyrene Chromophores for Semiconductor Sensitization: New Footprint Design. Tetrahedron 2007, 63, 7550-7559.

(10) Clark, C. C.; Meyer, G. J.; Wei, Q.; Galoppini, E. Tuning Open Circuit Photovoltages with Tripodal Sensitizers. J. Phys. Chem. B 2006, 110, 11044-11046.

(11) Lamberto, M.; Pagba, C.; Piotrowiak, P; Galoppini, E. Synthesis of Novel Rigid-Rod and Tripodal Azulene Chromophores. Tetrahedron Lett. 2005, 46, 4895-4899.

(12) Jeong, Y.; Han, J. W.; Kim, N.; Lee, Y.; Lee, C.; Hara, M.; Noh, J. Formation and Annealing Effect of Tolanethioacetate Self-Assembled Monolayers on $\mathrm{Au}(111)$. Bull. Korean Chem. Soc. 2007, 28, 2445-2448.

(13) Components of Os-trip were synthesized according to or similar to literature procedures and coupled via a Pd coupling. See refs 14-18 for literature procedures. Details will be published elsewhere.

(14) Jian, H.; Tour, J. M. En Route to Surface-Bound Electric FieldDriven Molecular Motors. J. Org. Chem. 2003, 68, 5091-5103. 
(15) Jukes, R. T. F.; Bozic, B.; Belser, P.; De Cola, L.; Hartl, F. Photophysical and Redox Properties of Dinuclear Ru and Os Polypyridyl Complexes with Incorporated Photostable Spiropyran Bridge. Inorg. Chem. 2009, 48, 1711-1721.

(16) Belser, P.; De Cola, L.; Hartl, F.; Adamo, V.; Bozic, B.; Chriqui, Y.; Iyer, V. M.; Jukes, R. T. F.; Kuhni, J.; Querol, M.; Roma, S.; Salluce, N. Photochromic Switches Incorporated in Bridging Ligands: A New Tool to Modulate Energy-Transfer Processes. Adv. Funct. Mater. 2006, 16, 195-208.

(17) Ramachandra, S.; Schuermann, K. C.; Edafe, F.; Belser, P.; Nijhuis, C. A.; Reus, W. F.; Whitesides, G. M.; De Cola, L. Luminescent Ruthenium Tripod Complexes: Properties in Solution and on Conductive Surfaces. Inorg. Chem. 2011, 50, 1584-1591.

(18) Ramachandra, S.; Polo, F.; Edafe, F.; Schuermann, K. C.; Nijhuis, C. A.; Belser, P.; Reus, W. F.; Whitesides, G. M.; De Cola, L. Luminescent Acetylthiol Derivative Tripodal Osmium(II) and Iridium(III) Complexes: Spectroscopy in Solution and on Surfaces. Pure Appl. Chem. 2011, 83, 779-799.

(19) Kalyanamasundaram, K. Photochemistry of Polypyridine and Porphyrin Complexes; Academic Press: San Diego, 1992.

(20) Larsen, R. E.; Glover, W. J.; Schwartz, B. J. Does the Hydrated Electron Occupy a Cavity?. Science 2010, 329, 65-69.

(21) Yamamoto, K.; Imaoka, T.; Chun, W. J.; Enoki, O.; Katoh, H.; Takenaga, M.; Sonoi, A. Size-Specific Catalytic Activity of Platinum Clusters Enhances Oxygen Reduction Reactions. Nat. Chem. 2009, 1, 397-402.

(22) Peruffo, M.; Contreras-Carballada, P.; Bertoncello, P.; Williams, R. M.; De Cola, L.; Unwin, P. R. Potential-Assisted Assembly of Functionalised Platinum Nanoparticles on Electrode Surfaces. Electrochem. Commun. 2009, 11, 1885-1887.

(23) Busby, M.; Chiorboli, C.; Scandola, F. Relaxation Dynamics and Transient Behavior of Small Arenethiol Passivated Gold Nanoparticles. J. Phys. Chem. 2006, 110, 6020-6026.

(24) Kober, E. M.; Caspar, J. V.; Lumpkin, R. S.; Meyer, T. J. Application of the Energy-Gap Law to Excited-State Decay of Osmium(II) Polypyridine Complexes - Calculation of Relative Nonradiative Decay-Rates from Emission Spectral Profiles. J. Phys. Chem. 1986, 90, 3722-3734.

(25) Schindewolf, U.; Wüntschel, P. Comparison of Solvated Electron Reaction-Rates in Water and Ammonia. Can. J. Chem. 1977, 55, 2159-2164.

(26) Furube, A.; Asahi, T.; Masuhara, H.; Yamashita, H.; Anpo, M. Direct Observation of a Picosecond Charge Separation Process in Photoexcited Platinum-Loaded $\mathrm{TiO}_{2}$ Particles by Femtosecond Diffuse Reflectance Spectroscopy. Chem. Phys. Lett. 2001, 336, 424-430.

(27) Kotani, H.; Ohkubo, K.; Takai, Y.; Fukuzumi, S. ViologenModified Platinum Clusters Acting As an Efficient Catalyst in Photocatalytic Hydrogen Evolution. J. Phys. Chem. B 2006, 110, 24047-24053.

(28) Hare, P. M.; Price, E. A.; Bartles, D. M. Hydrated Electron Extinction Coefficient Revisited. J. Phys. Chem. A 2008, 112, 6800-6802.

(29) Keene, J. P. The Absorption Spectrum and Some Reaction Constants of the Hydrated Electron. Radiat. Res. 1964, 22, 1-13.

(30) Shida, T.; Iwata, S.; Watanabe, T. Electronic Absorption Spectra of Excess Electrons in Molecular Aggregates. II. Solvated Electrons. J. Phys. Chem. 1972, 76, 3691-3694.

(31) Schindewolf, U. Solvatisierte Elektronen. Chem. Unserer Zeit 1970, 4, 37-43.

(32) Dorfman, L. M.; Jou, F. Y.; Wageman, R. Solvent Dependence of the Optical Absorption Spectrum of the Solvated Electron. Ber. Bunsen-Ges. 1971, 75, 681-685.

(33) Walker, D. C.; Wallace, S. C. Pulse Radiolysis of Formamide and Formamide-Water Mixtures. Can. J. Chem. 1971, 49, 3398-3401.

(34) Lampre, I.; Bonin, J.; Soroushian, B.; Pernot, P.; Mostafavi, M. Formation and Solvation Dynamics of Electrons in Polyols. J. Mol. Liq. 2008, 114, 124-129.

(35) Lin, M.; Fu, H.; Lampre, I.; de Waele, V.; Muroya, Y.; Yan, Y.; Yamashita, S.; Katsumura, Y.; Mostafavi, M. Pulse Radiolysis Studies on the Temperature-Dependent Spectrum and the Time-Dependent Yield of Solvated Electron in Propane-1,2,3-triol. J. Phys. Chem. A 2009, 113, 12193-12198.

(36) Muroya, Y.; Lin, M.; de Waele, V.; Hatano, Y.; Katsumura, Y.; Mostafavi, M. First Observation of Picosecond Kinetics of Hydrated Electrons in Supercritical Water. J. Phys. Chem. Lett. 2010, 1, 331-335. 